\title{
Resistance to Races 0, 1, and 2 of Fusarium Wilt of Watermelon in Citrullus sp. PI-296341 -FR
}

R.D. Martyn

Department of Plant Pathology \& Microbiology, Texas A\&M University, College Station, TX 77843

\section{Netzer}

Plant Protection Institute, The Volcani Center, Bet Dagan, Israel

\section{Additional index words. Fusariurn oxysporum f. sp. niveum, Citrullus lanatus}

Fusarium wilt of watermelon [Citrullus lanatus (Thunb.) Matsum. \& Nakai] is caused by Fusarium oxysporum Schlecht. (emend. Snyd. \& Hans.) f. sp. niveum (E.F. Sm.). The disease was first described by Smith (1894) from South Carolina and Georgia in the United States. It is now well-established throughout the watermelon-growing regions of the world. Once a field is infested, the Fusarium wilt pathogen may survive for many years and can seriously limit watermelon production in those fields. Long-term crop rotation (5 to 10 years) and leaving the soil fallow for several years helps reduce the pathogen population in the soil, but generally does not eradicate the pathogen. Even in cases where the pathogen is reduced to noneconomic levels, reintroduction via contaminated soil or seed is possible.

Over the years, attempts to control Fusarium wilt have focused on several approaches, including soil polarization (Martyn and Hartz, 1986), induced resistance (Biles and Martyn, 1989; Davis, 1967; Shimotsuma et al., 1972), cultural practices (Hopkins and Elmstrom, 1976; Jones et al., 1975; Sun and Huang, 1985), fumigation (Hopkins and Elmstrom, 1979), and grafting (Kuniyasu, 1981). However, genetic resistance has

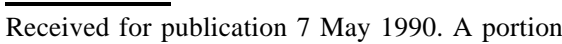
of this research was performed while D. Netzer was on sabbatical leave in the Dept. of Plant Pathology and Microbiology, Texas A\&M Univ. The technical assistance of E.A. Dillard, III is gratefully acknowledged. The cost of publishing this paper was defrayed in part by the payment of page charges. Under postal regulations, this paper therefore must be hereby marked advertisement solely to indicate this fact. consistently proven to be the most effective and efficient means of control (Elmstrom and Hopkins, 1981; Hopkins and Elmstrom, 1984).

Watermelon cultivars resistant to Fusarium wilt have been released from many breeding programs, beginning with W.A. Orton (Orton, 1907). Many of these, however, have succumbed to wilt over the years due to the pathogenic variability of the fungus. At present, there are three described races of $F$. o. f. sp. niveum: races 0,1 , and 2 (Cirulli, 1972; Martyn, 1987). The most recently described is race 2 , first observed in Israel (Netzer, 1976; Netzer and Dishon, 1973 ) in 1973 and in the United States in 1981 (Martyn, 1985, 1987). Race 2 is now present in Florida and Oklahoma (Martyn and Bruton, 1989). Many cultivars have high wilt resistance to isolates of races 0 and 1 ; however, race 2 is more aggressive and overcomes all currently known wilt-resistant cultivars.

In 1978 , shortly after $F$. o. f. sp. niveum race 2 was described in Israel, a screening program for resistance to race 2 was initated by D. Netzer. Over 10 years, 138 Citrullus spp. PI accessions, a $C$. colocynthis native to Israel, two wild species native to equatorial Africa (C. rehmii and C. ecirrhosus), and 65 domestic watermelon cultivars $(C$. lanatus) were screened against the Israeli race 2 isolate (IS-59) by the root-dip inoculation technique. None of the entries expressed resistance to race 2 when tested in the seedling stage (10 days old). However, in the original planting, one PI accession (PI-296341) did segregate into resistant and susceptible plants when inoculated at the 3-week stage.

This paper presents the results of several successive studies with PI-296341 conducted in Texas to select for improved race 2-resistance. In addition, wilt resistance evaluations were conducted with several geographic isolates of races 0,1 , and 2 as well as with three inoculation techniques. PI-296341 -FR is being released by the Texas Agricultural Experiment Station as an improved PI germplasm line with wilt resistance to races 0,1 , and 2 of $F . o$. f. sp. niveum.

\section{Origin}

PI-296341 (Citrullus sp.) was collected from the Republic of South Africa under the local name of 'Tsamma' by the Dept. of Agricultural Technical Services, Pretoria, and was deposited with the U.S. Plant Introduction Station in Beltsville, Md. in 1964.

\section{Evaluation of wilt resistance}

The original planting and inoculation of PI-296341 with the Israeli isolate of race 2 (IS-59) resulted in a segregated progeny of $\approx 3$ susceptible : 1 resistant. Surviving plants were collected, planted in the field or greenhouse in Israel, and selfed for three generations. Each generation was screened for resistance to IS-59 at the 3-week stage. After three selfings, resistance to IS-59 in PI-296341 was $\approx 85 \%$.

In 1988, the improved line (PI-296341$F R$ ) was evaluated for resistance to $F$. $o$. f. sp. niveum race 2 in Texas (Netzer and Martyn, 1989). In these studies, three isolates of race 2 were used: IS-59 (Israel), TX-XID (Texas), and OK-270 (Oklahoma). Threeweek-old plants were root-dip inoculated as described previously (Martyn, 1987; Netzer and Martyn, 1989) using $1.5 \times 10^{6}$ microconidia/ml. PI-296341 -FR was $90 \%$ to $95 \%$ resistant to all three isolates after 4 weeks, whereas Calhoun Gray (resistant to races 0 and 1) was $100 \%$ wilted. Apparently, unlike numerous other cultivars, high inoculum

Table 1. Watermelon differentials used to separate pathological races of Fusarium oxysponum f. sp. niveum.

\begin{tabular}{lccc}
\hline \hline \multirow{2}{*}{$\begin{array}{l}\text { Host } \\
\text { differential }\end{array}$} & 0 & 1 & 2 \\
\cline { 2 - 4 } Black Diamond & $\mathrm{S}$ & $\mathrm{S}$ & $\mathrm{S}$ \\
Charleston Gray & $\mathrm{R}$ & $\mathrm{S}$ & $\mathrm{S}$ \\
Calhoun Gray & $\mathrm{R}$ & $\mathrm{R}$ & $\mathrm{S}$ \\
PI-296341-FR & $\mathrm{R}$ & $\mathrm{R}$ & $\mathrm{R}$ \\
\hline
\end{tabular}

${ }^{\mathrm{x}} \mathrm{S}=$ susceptible, $\mathrm{R}=$ resistant. 


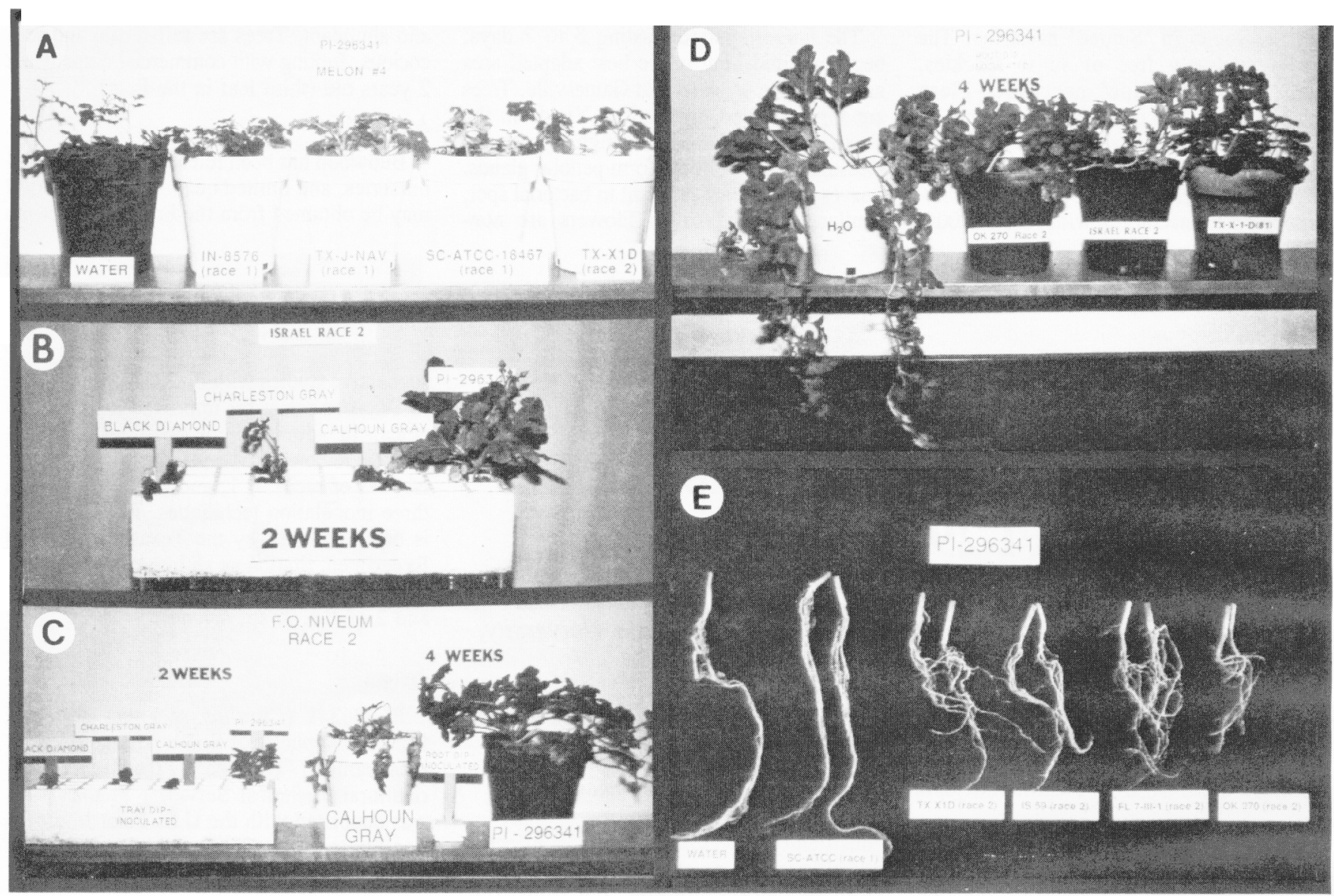

Fig. 1. Disease reaction of PI-296341 -FR inoculated by several methods with various races and isolates of F.o. f. sp. niveum. (A) Comparison of 2-weekold PI-296341 -FR plants root-dip inoculated with three isolates of race 1 and one isolate of race 2. There is a slight stunting of the plants, but no wilt or deaths; (B) watermelon differential cultivars (see Table 1) inoculated with the Israeli isolate of race 2 (IS-59); only PI-296341FR is resistant; (C) comparison of tray-dip inoculated and root-dip inoculated plants with a Texas race 2 (X-1-D); all PI-296341 -FR plants were resistant by both inoculation methods while the differentials were susceptible; (D) comparison of 4-week-old PI-296341 - FR plants inoculated with three isolates of race 2 with a water control plant showing moderate stunting of inoculated plants; (E) comparison of roots from PI-296341 - FR plants inoculated with a race 1 isolate and four isolates of race 2 showing reduced root mass caused by race 2 , but not by race 1 .

concentration has little effect on the wilt resistance of PI-296341 -FR plants (Martyn and McLaughlin, 1983).

In 1989, PI-296341 -FR was sib-increased in the greenhouse and once again evaluated for resistance to race 2; this time, four isolates (IS-59, TX-XID, OK-270, and FL-7III1) and three inoculation techniques (root dip, tray dip, and infested soil plots) were used. Two-week-old seedlings were root-dipped for $30 \mathrm{sec}$ in $1 \times 10^{6}$ microconidia $/ \mathrm{ml}$ of each of the four race 2 isolates and transplanted to $1650-\mathrm{cm}^{3}$ pots containing a 4 pasteurized sand : 1 peat : 1 vermiculite mix (by volume). There were four seedlings per pot and five replicated pots for each treatment. For the tray-dip inoculation, seeds were sown in polystyrene foam trays with $40-\mathrm{cm}^{3}$ cells containing pasteurized sand-peat-vermiculite mix and placed inside a larger flat containing a $2.5-\mathrm{cm}$ layer of peat moss. After 14 to 16 days, the roots of the seedlings had grown through the drainage holes of the polystyrene trays and into the peat moss of the larger flat. At this time, the trays were removed and the roots of all seedlings were uniformly trimmed to $2.5 \mathrm{~cm}$. The trays were then placed individually into plastic trays containing $250 \mathrm{ml}$ of $1 \times 10^{6}$ microconidia/ $\mathrm{ml}$ of each isolate for $10 \mathrm{~min}$, after which they were returned to the larger peat moss flats in a growth chamber. Disease symptoms (stunting, wilting, and death) were monitored daily for 4 weeks for both the rootdip and tray-dip experiments.

For the infested soil test, the Texas isolate (TX-XID) was grown in 9 sterile sand : 1 corn meal (v/v) for 1 month and then $200 \mathrm{~g}$ was uniformly distributed into methylbromide-treated field microplots $(0.6 \mathrm{~m} \times 1.0$ $\mathrm{m})$ to a depth of $30 \mathrm{~cm}$. Established populations of $F . o$. f. sp. niveum race 2 after 2 weeks ranged from 3500 to $10,500 \mathrm{cfu} / \mathrm{g}$ soil. Three-week-old seedlings were transplanted into the microplots (four per microplot) and fertilized with $14 \mathrm{~N}-14 \mathrm{P}-14 \mathrm{~K}$ encapsulated Osmocote. Plants were maintained insect- and foliar pathogen-free with timely applications of registered pesticides, and plants were allowed to grow to maturity. Disease assessment was made daily throughout the entire season.

In each inoculation test, equal numbers of Calhoun Gray plants were inoculated iden- tically to serve as positive disease checks. Seedlings of both PI-296341 -FR and Calhoun Gray inoculated with water or transplanted into noninfested microplot soil were used as negative disease checks.

In a separate inoculation test, PI-296341$F R$ was root-dip inoculated with three isolates of F.o. f. sp. niveum race 1 [ATCC18467 (South Carolina), IN-8576 (Indiana), and TX-J-Nav (Texas) and one isolate of race 0 (FL-60-3A)]. Conditions were the same as described above.

PI-296341 -FR plants were resistant $(0 \%$ to $5 \%$ wilt) to all four isolates of race 2 by each inoculation method (Fig. 1 A-E). In contrast, Calhoun Gray plants were susceptible ( $75 \%$ to $100 \%$ wilt) to each isolate of race 2 and by each inoculation method. In addition, PI-296341 -FR was $100 \%$ resistant to the three isolates of race 1 and one isolate of race 0 by the root-dip inoculation method (Fig. 1A) (data for race 0 are not shown).

Although PI-296341 -FR plants did not die when inoculated with race 1 or race 2 isolates, they were stunted and had a smaller root mass compared to water-inoculated control plants (Fig. 1 A, D, E). Stunting was 

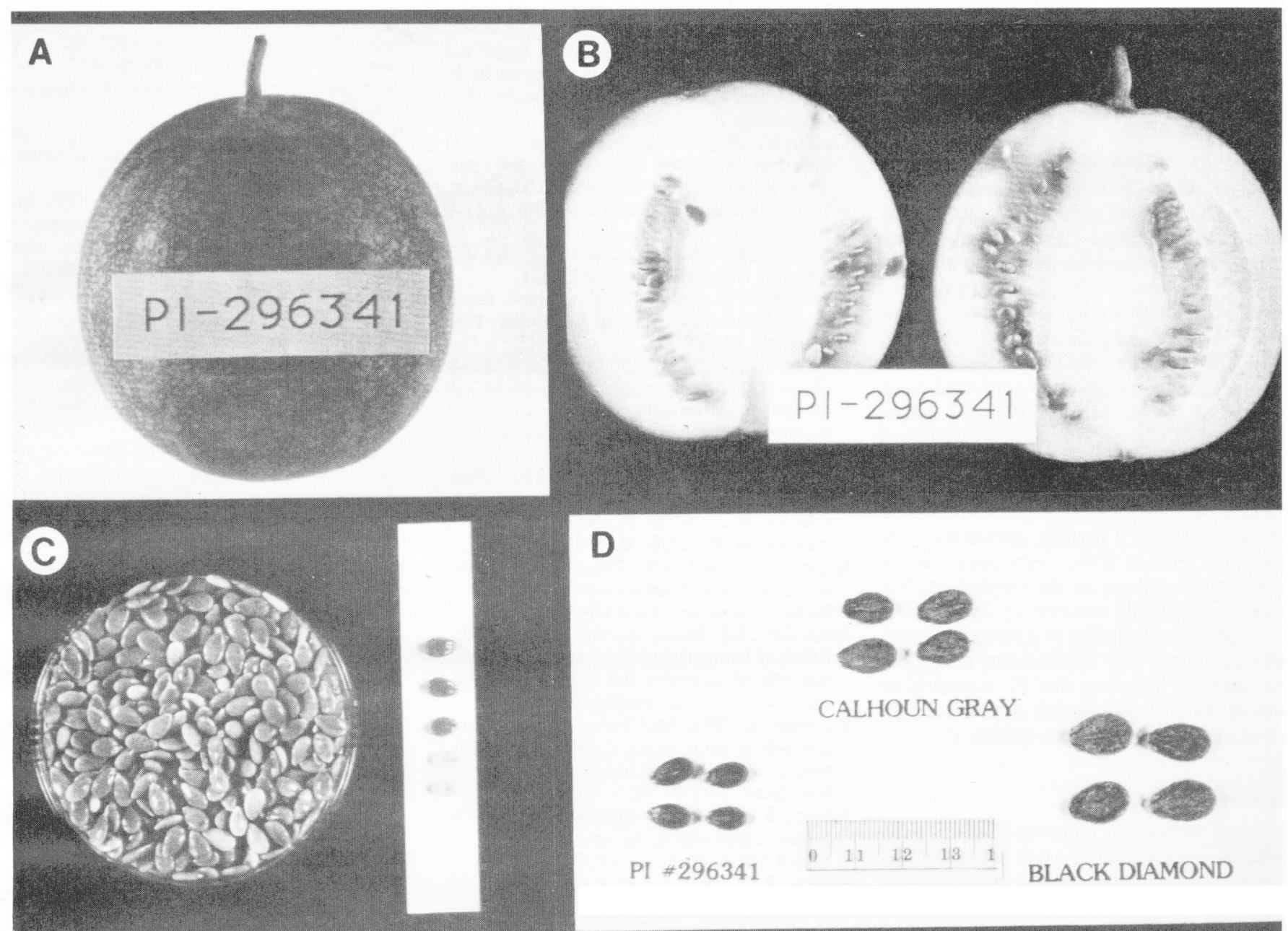

D
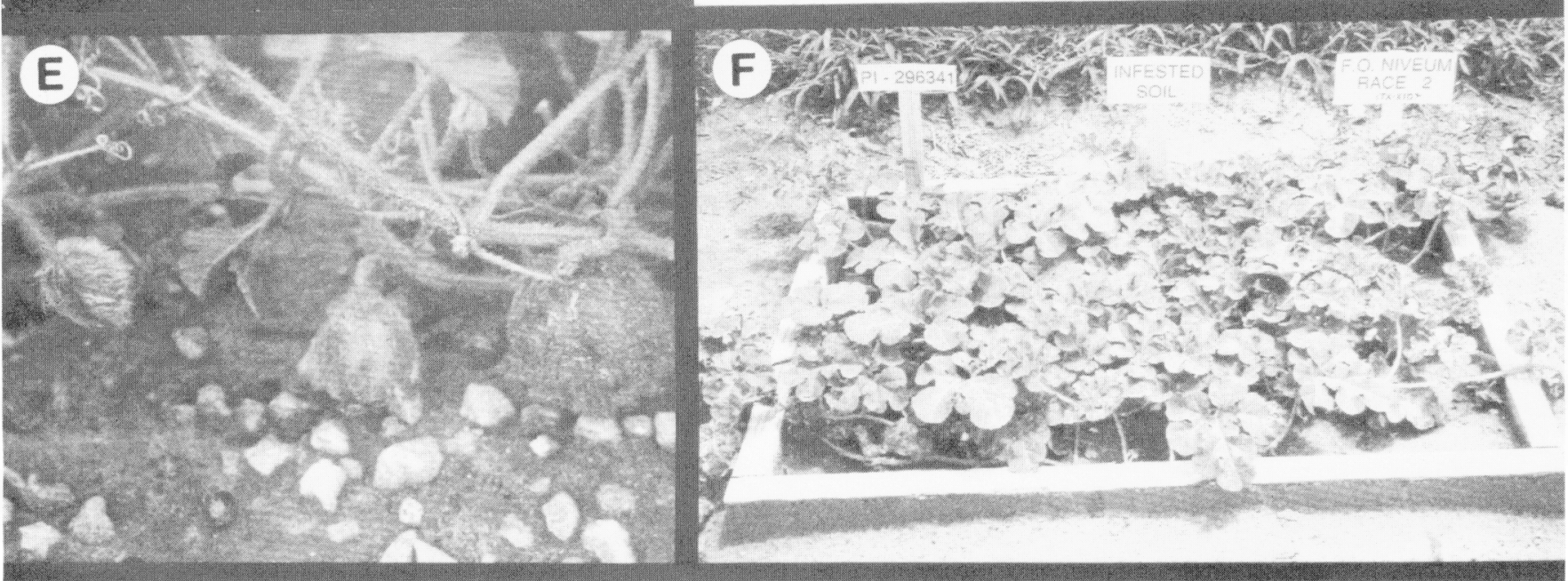

Fig. 2. Fruit and seed characteristics of watermelon PI-296341-FR. (A) mature fruit; size ranges from $\approx 10$ to $15 \mathrm{~cm}$ diameter and 500 to $1200 \mathrm{~g}$; (B) mature fruit showing the characteristic white flesh and seed cavity, $(\mathbf{C})$ mature seeds $(\approx 300)$ harvested from one melon. Seeds show increasing maturity from white to olive-green. Seed coats turn brown after drying; (D) size comparison of seed from PI-296341 - FR, Calhoun Gray, and Black Diamond; (E) young fruit showing characteristic pubescence; $(\mathbf{F}) \approx 60$-day-old vines of PI-296341 -FR growing in soil infested with F.o. f. sp. niveum race 2.

more pronounced in race 2-inoculated plants (Fig. 1D); however, some random and lesser degree of stunting occurred in plants inoculated with race 1 , most noticeably with the ATCC 18467 isolate (Fig. 1A). Stunting was not evident in race 0 -inoculated plants. No yellowing of the foliage was associated with any of the race 0 or race 1 isolates, but minor yellowing was observed on some plants inoculated with the race 2 isolates. Fusarium $o$. f. sp. niveum could be isolated from the roots of inoculated PI-296341 -FR plants, but not from the stem above the crown. In contrast, race 2 was routinely isolated from the stems of infected Calhoun Gray plants. Thus, resistance in PI-296341 -FR to F.o.f. sp. ni- veum appears to be substantial but incomplete. There is still some low-level segregation occurring in PI-296341 -FR as occasionally several plants $(\leq 5 \%)$ may die. Inheritance studies to determine how the resistance is conferred have not been done. Resistance to race 1 has been shown to be inherited as a single dominant gene (Netzer and Weintall, 
1980). It is known, however, that the gene or genes in PI-296341 -FR confer(s) resistance to all three races of F.o. f. sp. niveum.

\section{Fruit description}

PI-296341 - FR produces a small (500 to $1200 \mathrm{~g}$ ), round ( 10 to $15 \mathrm{~cm}$ diameter) grayish-green fruit with numerous $(\geq 300)$ small $(5 \times 10 \mathrm{~mm})$, olive-green to brown seeds (Fig. 2 A-D). Approximate days to maturity is 80 . The flesh is white (Fig. 2B) and lacks any noticeable flavor but is not bitter. When small, the fruit is pubescent but loses that trait after several weeks (Fig, 2E). The vine is small-leaved compared to cultivated types and has numerous runners (Fig. 2F). Flowering begins after $\approx 1$ month and continues throughout the life of the plant.

Germination is very poor $(<10 \%)$ on freshly harvested seed. However, if the seed is stored for 2 to 3 months, germination approaches $85 \%$ to $95 \%$. Seed coats have a tendency to adhere to the cotyledons, but most can be easily removed by hand.

In addition to serving as a potential source of resistance to race 2 in breeding programs, we propose including this PI accession as one of the host differentials used to identify races of F.o. f. sp. niveum (Table 1).

\section{Availability}

Small amounts of improved PI-296341 -FR seed are available to research personnel and commercial companies. Contact R.D.M. for information.

\section{Literature Cited}

Biles, C.L. and R.D. Martyn. 1989. Local and systemic resistance induced in watermelons by formae speciales of Fusarium oxysporum. Phytopathology 79:856-860.

Cirulli, M. 1972. Variation of pathogenicity in Fusarium oxysporum f. sp. niveum and resistance in watermelon cultivars. Actas Congr. Union Fitopathol. Mediter. Oeiras, 3rd. p. 491500 .

Davis, D. 1967. Cross protection in Fusarium wilt diseases. Phytopathology 57:311-314.

Elmstrom, G.W. and D.L. Hopkins. 1981. Resistance of watermelon cultivars to Fusarium wilt. Plant Dis. 65:825-827.

Hopkins, D.L. and G.W. Elmstrom. 1976. Effect of soil $\mathrm{pH}$ and nitrogen source on Fusarium wilt of watermelon on land previously cropped in watermelons. Proc. Fla. State Hort. Soc. 89:141143.

Hopkins, D.L. and G.W. Elmstrom. 1979. Evaluation of soil fumigants and application methods for the control of Fusarium wilt of watermelon. Plant Dis. Rptr. 63:1003-1006.

Hopkins, D.L. and G.W. Elmstrom. 1984. Fusarium wilt in watermelon cultivars grown in a 4-year monoculture. Plant Dis. 68:129-131.

Jones, J.P., S.S. Woltz, and P.H. Everett. 1975. Effect of liming and nitrogen source on Fusarium wilt of cucumber and watermelon. Proc. Fla. State Hort. Soc. 88:200-203.

Kuniyasu, K. 1981. Seed transmission of Fusarium wilt of bottle gourd, Lagenaria siceraria, used as a root stock of watermelon. Jpn. Agr. Res. Quart. 14:157-162.

Martyn, R.D. 1985. An aggressive race of $\mathrm{Fu}$ sarium oxysporum $\mathrm{f}$. $\mathrm{sp}$. niveum new to the United States. Plant Dis. 69:1007.

Martyn, R.D. 1987. Fusarium oxysporumf. sp. niveum race 2: A highly aggressive race new to the United States. Plant Dis. 71:233-236.

Martyn, R.D. and B.D. Bruton. 1989. An initial survey of the United States for races of Fusarium oxysporum f. sp. niveum. HortScience 24:696-698.

Martyn, R.D. and T.K. Hartz. 1986. Use of soil polarization to control Fusarium wilt of watermelon. Plant Dis. 70:762-766.

Martyn, R.D. and R.J. McLaughlin. 1983. Effects of inoculum concentration on the apparent resistance of watermelons to Fusarium oxysporum f. sp. niveum. Plant Dis. 67:493-495.

Netzer, D. 1976. Physiological races and soil population levels of Fusarium wilt of watermelon. Phytoparasitica 4:131-136.

Netzer, D. and R.D. Martyn. 1989. PI-296341, a source of resistance in watermelon to race 2 of Fusarium oxysporum f. sp. niveum. Plant Dis. 73:518.

Netzer, D. and I. Dishon. 1973. Screening for resistance and physiological specialization of Fusarium oxysporum in watermelon and muskmelon. 2nd Intl. Congr. Plant Pathol., Minneapolis, MN. (Abstr.)

Netzer, D. and C. Weintall. 1980. Inheritance of resistance in watermelon to race 1 of Fusarium oxysporum f. sp. niveum. Plant Dis. 64:853854.

Orton, W.A. 1907. On methods of breeding for disease-resistance. Proc. Soc. Hort. Sci. 5:28.

Shimotsuma, M., J. Kuc, and C.M. Jones. 1972. The effects of prior inoculations with non-pathogenic fungi on Fusarium wilt of watermelon. HortScience 7:72-73.

Smith, E.F. 1894. The watermelon disease of the South. Proc. Amer. Assn. Adv. Sci. 43:289290.

Sun, S.K. and J.W. Huang. 1985. Formulated soil amendment for controlling Fusarium wilt and other soilborne diseases. Plant Dis. 69:917-920. 